\title{
USE OF DIAGNOSTIC STRAINS OF SALMONELLA/MICROSOME ASSAY TO COMPARE THE MUTAGENICITY OF ATMOSPHERIC PARTICULATE MATTER FROM LIMEIRA AND KYOTO.
}

\section{Macelle C. G. Giron*, Bianca de S. Maselli, Hwanmi Lim, Roger Westerholm, Kristian Dreij, Tetsushi Watanabe, Fábio Kummrow, Gisela de A. Umbuzeiro.}

\begin{abstract}
According to the International Agency for Research on Cancer (IARC), exposure to air pollution and particulate matter (PM) is carcinogenic to humans (Group 1). Among the classes of compounds present in MP are polycyclic aromatic hydrocarbons (PAH) and their derivatives, pollutants known for their pro mutagenicity and carcinogenicity. The formation of its derivatives is influenced by sources of contamination, atmospheric and climatic characteristics. Based on this, it was used the Salmonella/microsome microsuspension assay with different diagnostic strains to evaluate the mutagenicity of PM samples collected in Limeira and Kyoto.
\end{abstract}

\section{Key words:}

total particulate matter (PM), polycyclic aromatic hydrocarbons (PAHs), nitro and oxi-PAHs.

\section{Introduction}

Studies on the quality of air in urban environments are of great concern because many human activities can lead to air pollution and cause damage to human health and the environment (Callén et al., 2013) ${ }^{1}$. In addition, DeMarini $(2012)^{2}$ considers that there is already enough evidence that air pollution can be declared as mutagenic to human germ cells.

Composition of atmospheric PM is influenced by pollution sources, temperature and solar radiation. The average temperatures in Limeira and Kyoto during the winter are 20.4 and $6.5{ }^{\circ} \mathrm{C}$ and sunlight are $11 \mathrm{~h} /$ day for both. The two cities studied present environmental and climatic characteristics, levels and sources of emission of pollutants different, which can lead to each one of these cities presenting characteristic profiles of mutagens and mutagenic activity. The aim of this work was to compare the mutagenic profile of the organic extracts from pooled total PM samples collected in both cities

\section{Results and Discussion}

Samples were collected during winter in both sites and extracted by accelerated solvent extraction. The extractable organic matters (EOM) of each pool were determined. The Salmonella/microsome microsuspension assay (Image 1) was performed without and with S9 using the strains TA1538, TA98, YG5185 and YG1041.

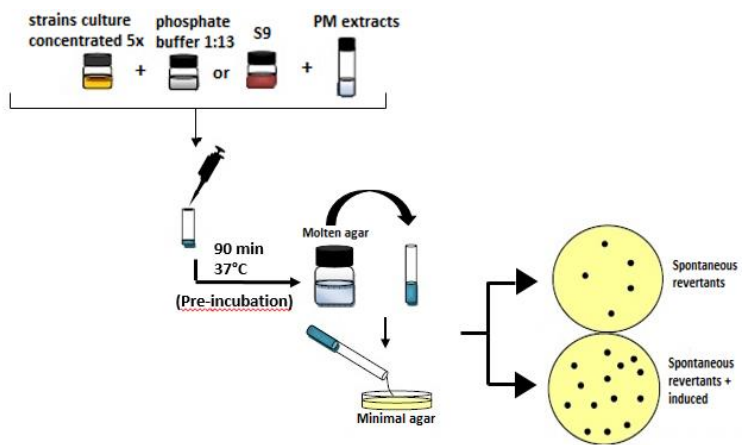

Image 1. Salmonella/microsome microsuspension assay

The extracts were mutagenic for all used strains and the highest mutagenicity was observed with YG1041, indicating an important contribution of nitro-compounds for the mutagenic responses of the samples.

When the mutagenicity results are expressed by air volume (rev./m3) (Chart 1), the sample of Limeira presented the higher potencies for all used strains without and with S9.

Chart 1. Mutagenic potencies, expressed in air volume (revertants $/ \mathrm{m}^{3}$ ), of the Limeira and Kyoto PM sample extracts.

\begin{tabular}{c|c|c|c|}
\hline \multicolumn{2}{c|}{ Strains } & \multicolumn{2}{c}{ Mutagenic potencies $\left(\mathrm{rev} . \mathrm{m}^{3}\right)$} \\
\cline { 3 - 4 } \multicolumn{2}{c|}{} & Limeira & Kyoto \\
\hline \multirow{2}{*}{ YG1041 } & - S9 & 2400 & 397 \\
\cline { 2 - 4 } & + S9 & 400 & 121 \\
\hline \multirow{2}{*}{ YG5185 } & - S9 & 27 & 4 \\
\cline { 2 - 4 } & + S9 & 9 & 3 \\
\hline \multirow{2}{*}{ TA98 } & $-S 9$ & 160 & 12 \\
\cline { 2 - 4 } & $+S 9$ & 18 & 3 \\
\hline \multirow{2}{*}{ TA1538 } & $-S 9$ & 151 & 23 \\
\cline { 2 - 4 } & + S9 & 89 & 13 \\
\hline
\end{tabular}

\section{Conclusions}

The mutagenic profiles of the samples collected in the both cities are very similar, despite the different in the pollution sources and environmental conditions. The differences in the climatic conditions of the studied cities do not seem to affect the PM mutagenicity profile, and the higher mutagenicity observed in the Limeira sample is probably associated with the higher PM level.

\section{Acknowledgement}

The authors acknowledge FAPESP (2015/23364-3) by the financial support. Macelle C.G. Giron acknowledges $\mathrm{CNPq}$ for the PIBIC scholarship. Bianca S. Maselli acknowledges CAPES by the PhD scholarship.

${ }^{1}$ Callén MS, López JM, Iturmendi A, Mastral AM. 2013. Nature and sources of particle associated polycyclic aromatic hydrocarbons (PAH) in the atmospheric environment of an urban area. Environ Pollut, 183:166-174.

${ }^{2}$ DeMarini DM. 2012. Declaring the existence of human germ-cell mutagens. Environ Mol Mutagen 53:166-172. 